\title{
Study on the Design Strategy of Electric Wheelchairs for People with Disabilities
}

\author{
Yi Feng \\ College of Arts and Design, Beijing Forestry University, Beijing, China
}

Keywords: product design, design strategy, electric wheelchair, humanization.

\begin{abstract}
In order to study the current design status, users' needs and product innovation design strategies of electric wheelchairs for the disabled in China, the target users' physiological characteristics, psychological characteristics and consumption habits are investigated and the basic classification of electric wheelchairs sold in China, the advantages and disadvantages of competitive products and the design features of domestic electric wheelchairs are analyzed. Based on these, the design innovation opportunities of electric wheelchairs for disabled persons were obtained, and the design innovation strategy of electric wheelchairs for disabled persons was given, which provides suggestions for the product innovation of electric wheelchairs for the manufacturers.
\end{abstract}

\section{Introduction}

China has the largest population in the world, and China is also the country with the largest population of the disabled in the world. According to the data released in the second national sample survey on the disabled in 2006, the total number of the disabled in China in 2006 accounted for 6.04\% of the country's total population, which was approximately 82.96 million. Compared with the data released in the first national sample survey on the disabled persons in 1987, the proportion of people with physical disabilities had significantly increased, and the proportion was also ranked first among all types of the disabled, which was approximately 24.12 million, accounting for $29.07 \%$. Persons with physical disabilities are caused by physical injuries that makes it difficult to perform certain activities in the normal way. They lack the ability to carry out certain activities, mostly manifested in their physical behavior, which also has great impact on their study, life and work. Compared with the normal people, there is no significant difference between their abilities of perception, memory, concentration and logical thinking and those of the normal ones.

Electric wheelchairs are the primary means of transportation for people with disabilities for daily travel and activities. In recent years, electric wheelchairs have gradually become popular among them. Driven by large marketing requirements, businessmen who lack technology accumulation and prefer short-term profits have begun their mass production in just a few months. The initial drawbacks are the safety accidents that accompanied the old generation's scooter, which makes the safety and popularization widely controversial. Therefore, research on electric wheelchairs for disabled people in China can provide strategic guidance for further improvement of the design of electric wheelchairs. On the other hand, it can promote the market development of electric wheelchairs, as well as the economic and social development.

\subsection{Research status of electric wheelchairs at home and abroad}

The United Kingdom was the first country to research intelligent wheelchairs. Many countries followed and began to invest in human and material resources to start research on smart wheelchairs. For example, SIAMD of Spain, a project starting from 1996, was based on the research of the disabled. It's a multi-functional system which is constructed according to the degree of disability of the disabled and the special needs of the users.

The study of French VAIM project started in 1989. This project carried out research on two generations of products. In the study of the first-generation system, the researchers concluded that the system included in this project should not only adapt to the physical and cognitive abilities of the special group of the disabled, but also integrated the morphological structure of the environment. 
Therefore, the second-generation products have been improved. The products have more functions, and they are more cost-effectiveness and extensive.

Compared with foreign countries, the development and research of electric wheelchairs in China started relatively late, especially in the research and development of smart wheelchairs. There are still large gaps compared with those foreign advanced technologies. However, with the continuous progress of science and technology, our researches have being also constantly self-improved. For example, the robotic wheelchair that can conduct human voice interaction carried out by the Institute of Automation of the Chinese Academy of Sciences has attracted much attention.

Although many countries have conducted various researches on electric wheelchairs, the starting points, research purposes, research methods, and technologies of each research are not the same. Therefore, each intelligent wheelchair's $R \& D$ ability to solve real problems is different. In the early development process of electric wheelchairs, the functions were generally relatively low-key and basically the same. For example, the simple movement of a wheelchair, the change control of the speed of movement and the obstacle avoidance function in the event of an obstacle. However, with the development of the times, the society is also making continuous progress. With the development of science and technology and continuous technological innovation, intelligent electric wheelchairs will be required to achieve more and more comprehensive functions, have better interactivity and functionality and be safer and more comfortable.

\subsection{Applications of electric wheelchairs in the disabled}

The general wheelchairs are designed for the disabled and the elderly. Because their lower limb disability which may cause inconvenience and is not conducive to daily walking, wheelchairs have become the means of transport for daily life. Wheelchairs allow the users to implement another "walking". Although some people with disabilities are disability-disabled, they are physically strong. However, some people with disabilities have worse physical fitness as they become older. The requirements of the wheelchairs for the same crowd are also different.

\section{Research on the Users}

\subsection{Physical characteristics of the disabled}

According to the survey, the general situation of the disabled in China is as follows:

Table 1 Classifications of five categories of persons with disabilities (including multiple disabilities)

\begin{tabular}{|c|c|c|c|c|c|}
\hline \multirow[b]{2}{*}{ Classifications } & \multirow{2}{*}{$\begin{array}{l}\text { Numbers } \\
\text { (10000) }\end{array}$} & \multicolumn{2}{|c|}{ Multiple disabilities } & \multirow{2}{*}{$\begin{array}{l}\text { The proportion of the total } \\
\text { number of persons with } \\
\text { disabilities (\%) }\end{array}$} & \multirow{2}{*}{$\begin{array}{l}\text { Current } \\
\text { disability } \\
\text { rate(\%) }\end{array}$} \\
\hline & & $\begin{array}{l}\text { Numbers } \\
(10000)\end{array}$ & $\%$ & & \\
\hline \multicolumn{6}{|l|}{ Listening } \\
\hline $\begin{array}{l}\text { language } \\
\text { disability }\end{array}$ & 2672 & 615 & 23.01 & 44.53 & 21.81 \\
\hline $\begin{array}{l}\text { Intellectual } \\
\text { disability }\end{array}$ & 1554 & 371 & 23.91 & 25.89 & 12.68 \\
\hline Visual disability & 1235 & 359 & 29.03 & 20.59 & 10.08 \\
\hline $\begin{array}{l}\text { Physical } \\
\text { disability }\end{array}$ & 1122 & 245 & 21.86 & 18.70 & 9.16 \\
\hline $\begin{array}{l}\text { Psychiatric } \\
\text { Disability }\end{array}$ & 303 & 78 & 25.60 & 5.05 & 2.47 \\
\hline Total & 6000 & 782 & 13.03 & 100.00 & 48.97 \\
\hline
\end{tabular}

The physically disabled over six years old:

Living ability: $38.06 \%$ of them can take care of themselves; $47.45 \%$ of them can partly take care of themselves; $14.49 \%$ of them cannot take care of themselves. 
Activity capacity: $47.62 \%$ of them can go to the street; $33.70 \%$ of them can walk around the household; $18.68 \%$ of them cannot walk.

5.171 million people are with disabled lower limbs; 1.283 million people are with disabled trunks; and 2.752 million people are with multiple disabilities. 11.22 million people are physically disabled.

The classifications of the disabled are shown in Table 1.

\subsection{Mental characteristics of the disabled}

Inferiority: Some genetic or accidental accidents result in some dysfunction or loss of the body. The disabled, therefore, pay close attention to the other people's thought of themselves. They often feel that they are being despised or inferior to others, and their personality gradually becomes introverted, lonely and timid. Then they may become depressed and loses the confidence in life.

Frustration: Due to physical disabilities, the disabled encounter many difficulties in their studies, lives and employment. They do not receive enough support and help. Those are easy for a healthy person are very difficult for the disabled. In the end, their frustration will arise. Especially the persons with disabilities who are caused by human accidents or causes, they become disabled from healthy, which causes a greater sense of frustration, and sometimes even changes a person's overall mental outlook and personality.

Sensitivity: Disability status can lead to the distractions of people with disability. They pay excessive attention to others' attitudes toward themselves and are extremely sensitive to the others' evaluation. Other people's pejorative, inappropriate and even unintentional names about themselves often arouse their resentment.

Loneliness: Due to physical deficiencies, the activities of the disabled are limited, and they are less likely to communicate with non-disabled people. Apart from the reason that they have not the same communication topic, it is also related to inconvenient communication. Because of the lack of normal communication and friends, loneliness will occur over time and it will gradually increase with age.

Complaint: The disabled always complain about their parents, their loved ones, and their fate. They feel that God is unfair to themselves. They are alone and different and they may consider himself to be an extra person in the world. It is useless for them to born in this world.

Eager to be paid attention: After being physically disabled, they often develop self-pity in self-abasement. They think that being a vulnerable group deserves people's attention, sympathy and help. Those who are introverted and unwilling to express themselves tend to have gratefulness after receiving help.

\subsection{Consumption habits of persons with disabilities}

According to the analysis of the income of the disabled and the investigation of relevant departments, for the present, about 35\% of the disabled in our cities are still working. Even if they are not in work, there will be certain amount of retirement pension funds. The pro-people also subsidize persons with disabilities in material terms. This has also become a major aspect of income for people with disabilities. It can be seen that the disabled people's consumer market is greatly potential.

\section{Market Analysis}

\subsection{Basic classification of electric wheelchairs}

Electric wheelchairs are divided into indoor type, outdoor type and road type according to the usage requirements. The maximum speed of the indoor electric wheelchair is not more than $4.5 \mathrm{~km} / \mathrm{h}$. The maximum speed of the outdoor electric wheelchair is not more than $6.0 \mathrm{~km} / \mathrm{h}$. The maximum speed of the road type electric wheelchair is no more than $18 \mathrm{~km} / \mathrm{h}$.

\subsection{Analysis of competitive products}

The low-end electric wheelchair represented by the mutual-bearing electric wheelchair is priced around 1500-3000. The material is made of aluminum alloy. The body of the vehicle is light, and the front and rear are dual-controllable. The hand brake and foot pedal can be disassembled. Some brands, 
such as Jiuyuan, sell reclining wheelchairs. Usually, this kind of electric wheelchair will not keep long in service life. And they have less additional functions and are inconvenient in use.

The mid-end wheelchairs represented by green LvYi electric wheelchairs are usually priced around 4000-8000. The detail processing is more humane. The wheel is equipped with fenders, and the battery life is long and the handrails can be adjusted on the basis of low-end wheelchairs.

High-end electric wheelchairs represented by German KangYang electric wheelchairs are priced ranging from 10,000 to 100,000. According to different characteristics and different functions, there are some functional features, such as standing, adjusting seats and adapting to various terrains. Although with high safety performance and user-friendly details, the cost performance is lower than that of the low-end wheelchairs.

\subsection{Design features of domestic electric wheelchairs}

In the face of the consumer spending power of Chinese consumers, the electric wheelchairs sold in the market are mainly cost-effective brands, such as Corfu and HaoGe. Domestic wheelchairs started late and generally began after 2010. Their functions are gradually improved over time. However, the shape is cold and single and there is no excessive design. The electric wheelchairs in the market generally only meet the usage, lacking visual functions. There are few studies on the innovative features of electric wheelchairs. The electric wheelchairs always lack simple and forward-looking designs. Wheelchairs generally perform better in terms of safety and comfort. But the functionality is mainly dictated by the price of the brand, and the details of the design are generally ignored. The results of the design and analysis are shown in Figure 1.

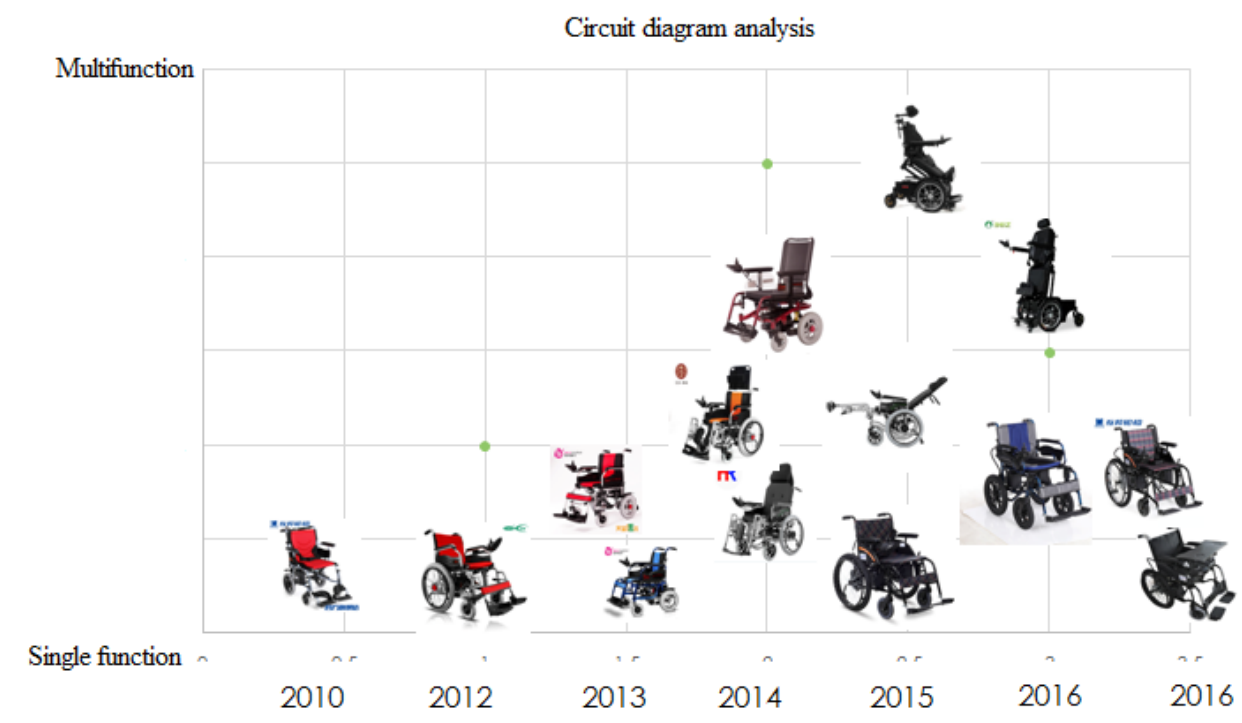

Figure 1 Design Analysis of Domestic Electric Wheelchair

\section{Innovation of Design Strategies}

According to the Research Status and Development of Intelligent Wheelchairs, three design trends of electric wheelchairs are proposed.

Firstly, the intelligent design strategy, which proposed that wheelchairs should be for practical applications and must be integrated with smart technologies.

Secondly, the humanized design strategy, which proposed that the designer should fully consider the needs of the mobility inconvenience, and proceed from the subtleties to design a safe, comfortable and reasonable intelligent wheelchair. For instance, the function that the wheelchair can be rose can make the disabled talk with others; choose a seat cushion with good air permeability; install alarm device; make wheelchair operation as simple as possible.

Thirdly, modular design strategy, which proposed that the wheelchairs should achieve modularization for mass production. The entire system should be composed of basic modules and 
various functional modules and each functional module is responsible for a function. Therefore, the users can choose according to their demands and configure the most appropriate wheelchair. At the same time, modularity can also reduce costs and increase cost-effectiveness. In terms of the appearance performance, the design of electric wheelchairs has gradually been improved from the simple and low-end functions to the better ones. The mainstream wheelchairs are still dominated by the traditional form, and the long-sized upright wheelchairs are also existing.

Therefore, the following design strategies are proposed for electric wheelchairs for people with disabilities in the current market.

Firstly, the security. That is, all the improvements that have been proposed must be under the premise of security, which is the most important.

Secondly, the convenient travel. We should strengthen the wheelchair's adaptability to the terrain and add some function modules that can be disassembled and assembled in the wheelchair according to the needs of different users, so that they can place some items. We can also design newer folding methods and structures. And reduce the space occupied by wheelchairs. The reverse combination of wheelchairs as a barrier-free furniture makes wheelchairs adaptable to some furniture.

Thirdly, the appearance of humanity. The cold appearance of a wheelchair often gives the user a feeling of inferiority and gives them a different look, so we can make some changes in the appearance of the wheelchair. In order to meet the users' requirements of different usage ways. The wheelchair may provide a body supporting mode instead of sitting. Some functions that are suitable for the disabled can be added. The disabled can also exercise in their wheelchair.

Fourth, the promotion of emotional communication. Electric wheelchairs can promote the interaction with people through the design of functions and institutions, and break the traditional monotonous model of pushing a wheelchair.

\section{References}

[1] Q. H. He, S. P. Huang, Z. X. Huang, et al. Research Status and Development Trend of Intelligent Wheelchairs [J]. Robotics and Applications, 2003, (2): 12-16.

[2] H. S. Wang. Investigation on Disabling Factors and Rehabilitation of Persons with Disabilities in Dongshan District of Guangzhou City [J]. Literatue and Information On Preventine Medicine, 2001.7 (2): 103-106.

[3] D. N. Ma, L. Lv, F. L. Song, et al. Design of Innovative Wheelchairs [J]. Modern Manufacturing Technology and Equipment, 2016, (1): 79-81.

[4] N. Yang. Research on Humanized Design of Multifunctional Electric Wheelchairs for the Elderly, [D]. Southwest Jiaotong University, 2015.

[5] F. H. Lu. Research and Analysis of Wheelchairs Climbing Stairs [D]. Northeastern University, 2007.

[6] C. X. Lu. Modular Research on the Use of Individual Vehicles for Persons with Physical Disabilities [D]. Hebei University of Technology, 2012.

[7] S. P. Huang. Research on Intelligent Wheelchair Navigation and Multisensor Information Fusion [D]. Central South University, 2003.

[8] Y. Ren. Intelligent Wheelchair Structure Design and Research [D]. Tianjin University of Science and Technology, 2009.

[9] Z. G. Chen, Manual Wheelchair Design and Research based on the Psychological Needs of the Disabled [D]. Southwest Jiaotong University, 2009. 